\title{
Effect of Al-addition on C-axis Orientation of Ba-ferrite Film Deposited on Amorphous Aluminum Oxide (a-AlO) Layer.
}

\author{
N. N. Shams, M. Matsumoto and, A. Morisako. \\ Dept. of Information Engineering, Shinshu University, 4-17-1 Wakasato, Nagano 380-8553, JAPAN.
}

In this study amorphous aluminum oxide ( $a$-AlO) was used as an underlayer to crystallize c-axis oriented Ba-ferrite (BaM) film. But coercivity of these films was going to decrease sharply below $20 \mathrm{~nm}$. A small amount of $\mathrm{Al}$ is added with $\mathrm{BaM}$ film with $a$-AlO underlayer. The substrate temperature $\left(T_{s}\right)$ was kept at $550^{\circ} \mathrm{C}$. Al content was varied from 0-4.5 atomic percent. Perfect $\mathrm{c}$-axis orientation of $\mathrm{BaM}$ thin film is possible with a small addition of $\mathrm{Al}$, even for the film of $10 \mathrm{~nm}$ with a $\Delta \theta_{50}$ of $2.5^{\circ}-2.8^{\circ}$. On the other hand, it was difficult to crystallize $\mathrm{BaM} / \mathrm{a}-\mathrm{AlO}$ film thinner than $25 \mathrm{~nm}$. Coercivity of $\mathrm{Al}-\mathrm{BaM} / a-\mathrm{AlO}$ films in perpendicular direction was higher than that of $\mathrm{BaM} / a-\mathrm{AlO}$ films, even for the thickness below $20 \mathrm{~nm}$.

Key words: Ba-ferrite, perpendicular magnetic recording, thin film

\section{Introduction}

The combination of high anisotropy field, excellent mechanical durability and better chemical stability makes hexagonal barium ferrite (BaM) an excellent candidate for perpendicular magnetic recording medium ${ }^{(1)}$. Much effort has been concentrated on c-axis orientation ${ }^{(2)}$ as well as the decrease of substrate temperature $\left(T_{s}\right)$ during deposition ${ }^{(3)}$ of $\mathrm{BaM}$ thin films for the high density perpendicular magnetic recording application. In order to prepare $\mathrm{BaM}$ thin films with $\mathrm{c}$-axis orientation on thermally oxidized silicon wafers $\left(\mathrm{SiO}_{2} / \mathrm{Si}\right)$, the substrate temperature have to be elevated to $620^{\circ} \mathrm{C}^{(4)}$. But it is strongly recommended to reduce the crystallization temperature during deposition for the practical fabrication of the recording medium. In addition Morisako et al. ${ }^{(5)}$ found that both $\mathrm{Ba}$ and $\mathrm{Fe}$ of $\mathrm{BaM}$ film deposited on $\mathrm{SiO}_{2} / \mathrm{Si}$ wafer substrate, diffused into the substrate. This may be due to the substrate heating at high temperature.

It has been found that structural and magnetic properties of thin films can be improved by using an appropriate substrate or seed layer ${ }^{(6)}$. According to Hylton et al. (1), a buffer layer between the film and substrate is necessary to minimize the interdiffusion between film and substrate.

In our previous study, an amorphous aluminum oxide (a-A1O) was used as an under-layer for BaM layer ${ }^{(7)}$. A high coercivity, $H_{c}$ of about $4.3 \mathrm{kOe}$ in perpendicular direction was obtained for film thickness $\left(\delta_{\mathrm{BaM}}\right)$ of $35 \mathrm{~nm}$ and grain size was reduced to about $20 \mathrm{~nm}$ for $\delta_{\mathrm{BaM}}$ of 20 $\mathrm{nm}$. But coercivity of these $\mathrm{BaM} / a-\mathrm{AlO}$ films was going to decrease sharply with decrease of film thickness especially below $20 \mathrm{~nm}$. In this study, $a$-AlO was also used as an under-layer to crystallize c-axis oriented BaM and in addition a small amount of $\mathrm{Al}$ is introduced into the BaM layer to increase the coercivity.

\section{Experimental Procedure}

The BaM/a-AlO thin films were deposited on thermally oxidized silicon wafers by using facing targets sputtering (FTS) system. After evacuating the chamber to a pressure below $1 \times 10^{-7}$ Torr, argon (Ar) and oxygen $\left(\mathrm{O}_{2}\right)$ gases were introduced and sputtering pressure was set at 2 mTorr. A pure Al metal disk was used to deposit the underlayer $(a-\mathrm{AlO})$ by reactive sputtering in presence of oxygen gas without any substrate heating. The thickness of a-AlO layer was kept constant at about of $10 \mathrm{~nm}$. Then BaM layer was deposited successively onto this $a$-AlO underlayer at the substrate temperature $\left(T_{s}\right)$ of $550^{\circ} \mathrm{C}$. The target for the deposition of BaM layer was sintered ferrite disks with the stoichiometric composition of $\mathrm{BaM}$ (i.e., $\mathrm{BaFe}_{12} \mathrm{O}_{\mathrm{x}}$ ). For the deposition of $\mathrm{BaM}$ film with $\mathrm{Al}$ (Al-BaM), a few Al plates with $2 \mathrm{~mm} \times 2 \mathrm{~mm}$ square were used along with the BaM target. Thickness of BaM layer $\left(\delta_{\mathrm{BaM}}\right)$ was varied from $10-35 \mathrm{~nm}$.

The crystallographic properties of the BaM films were characterized by x-ray diffractometry (XRD). X-ray photoemission spectroscopy (XPS) was used to analyze the amount of $\mathrm{Al}, \mathrm{Ba}$ and $\mathrm{Fe}$ in the $\mathrm{BaM} / \mathrm{a}-\mathrm{AlO}$ thin film after etching for 1 minute. Both the BaM film and a-AlO underlayer as well as silicon wafer substrate contain a large amount of oxygen $(\mathrm{O})$, which is difficult to analyze without any chemical analysis method. Due to this problem relative percentage of $\mathrm{Al}$ has been used in this study. The authors use following relation to estimate the $\mathrm{Al}$ content after analyzing the relative amount of $\mathrm{Al}$, $\mathrm{Ba}$ and $\mathrm{Fe}$ from the XPS data.

$\mathrm{Al}($ at. $\%)=[\mathrm{Al} /(\mathrm{Al}+\mathrm{Ba}+\mathrm{Fe})] \times 100$

This estimated values of $\mathrm{Al}(\mathrm{at} . \%)$ are relative values not the exact one. It is difficult to measure the exact value of $\mathrm{Al}$ content as some part of this $\mathrm{Al}$ may come from the a-AlO underlayer for very thin BaM layer. Magnetic properties of thin films were measured by vibrating sample magnetometer (VSM). Microstructure and morphological characteristics of the BaM films were investigated by scanning electron microscope (SEM).

\section{Results and Discussions}

At first, $\mathrm{Al}$ added $\mathrm{BaM}$ and $\mathrm{BaM}$ without any $\mathrm{Al}$ were deposited at a substrate temperature $\left(T_{s}\right)$ of $600^{\circ} \mathrm{C}$. From the XRD diagrams (not shown here), it was found that the intensity of $\mathrm{BaM}(00 l)$ plane was much stronger in case of $\mathrm{Al}-\mathrm{BaM}$ film than that of BaM film without $\mathrm{Al}$. This led 


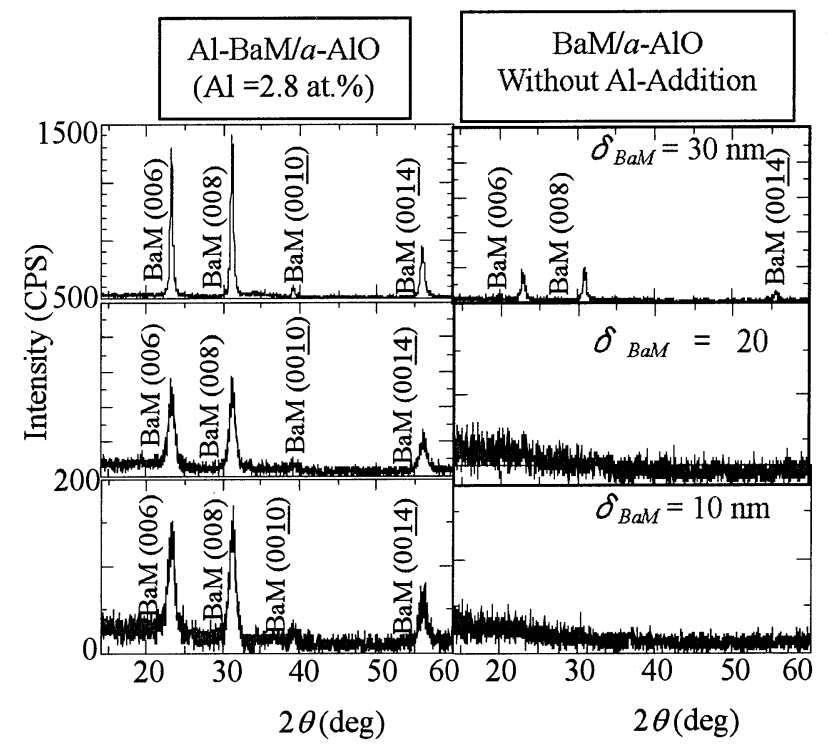

Fig. 1 X-ray diffraction diagram (XRD) of the BaM and $\mathrm{Al}-\mathrm{BaM}$ film deposited at a $T_{s}$ of $550^{\circ} \mathrm{C}$.

the authors to reduce the substrate temperature to $550^{\circ} \mathrm{C}$.

$\mathrm{X}$-ray diffraction diagram (XRD) of the $\mathrm{BaM}$ film deposited at $T_{s}$ of $550{ }^{\circ} \mathrm{C}$ is shown in the Fig.1. The presence of diffraction lines from $\mathrm{BaM}(00 l)$ planes reveals that all the films prepared by adding 2.8 at. \% Al shows perfect c-axis orientation even for the film thickness of $10 \mathrm{~nm}$. The intensity of these diffraction lines is also very strong. On the other hand, $\mathrm{BaM}$ films deposited at $550^{\circ} \mathrm{C}$ without any $\mathrm{Al}$-addition exhibit weaker diffraction lines for a film thickness of $30 \mathrm{~nm}$ and no peak is found when thickness is about $20 \mathrm{~nm}$. The $\mathrm{c}$-axis dispersion angle, $\Delta \theta_{5}$, which was measured as the full width at half maximum of the rocking curve of $\mathrm{BaM}$ (008) reflection, is as small as about a range of 2.5- 2.8 degree for all the Al-BaM ( $\mathrm{Al}=2.8 \mathrm{at} . \%)$ films. On the other hand, $\Delta \theta_{50}$ of $\mathrm{BaM}$ films without any $\mathrm{Al}$ is about

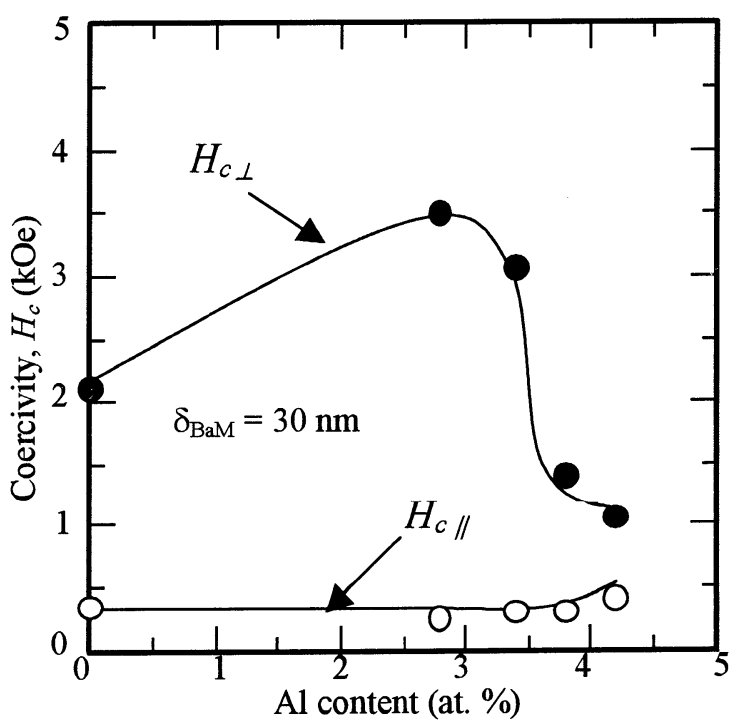

Fig. 2 Dependence of coercivity, $H_{c}$ of $\mathrm{BaM} / a-\mathrm{AlO}$ thin film as a function of $\mathrm{Al}$ content.

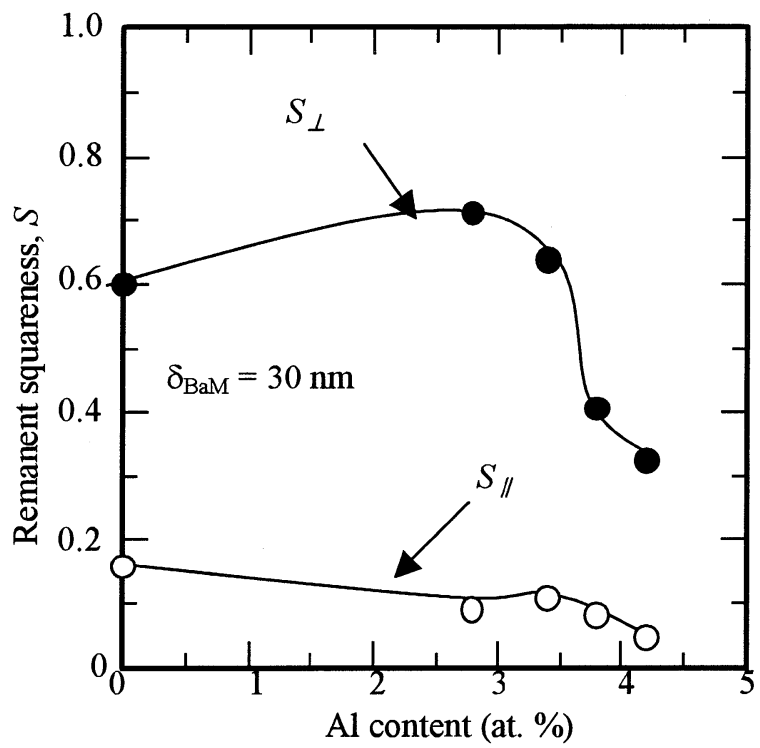

Fig. 3 Dependence of remanent squareness, $S$ of $\mathrm{BaM} / a-\mathrm{AlO}$ thin film as a function of $\mathrm{Al}$ content.

5.7-6 degree. This implies that an addition of $\mathrm{Al}$ enhances the c-axis orientation of BaM. Though the reason is not clear, $\mathrm{Al}$ atom may play a role to promote the nucleation of $\mathrm{BaM}$ crystals in the c-axis orientation.

Fig. 2 shows the dependence of coercivity as a function of $\mathrm{Al}$ content. It is found that coercivity in perpendicular direction $\left(H_{c \perp}\right)$ increases with a small increase of $\mathrm{Al}$ content $(2.8$ at.\% Al) then starts to decrease with increasing Al content whereas no significant change has been noticed in the in-plane coercivity $\left(H_{c} / /\right)$. The highest coercivity, $H_{c \perp}$ is found when only 2.8 at. $\% \mathrm{Al}$ is added to the BaM layer. Similar trend is also found from the remanent squareness values, $S$, as shown in the Fig.3. Perpendicular squareness ratio $\left(S_{\perp}\right)$ increases with a small increase of $\mathrm{Al}$ content $(2.8 \mathrm{at} . \% \mathrm{Al})$ then starts to decrease with increasing Al contents while in-plane

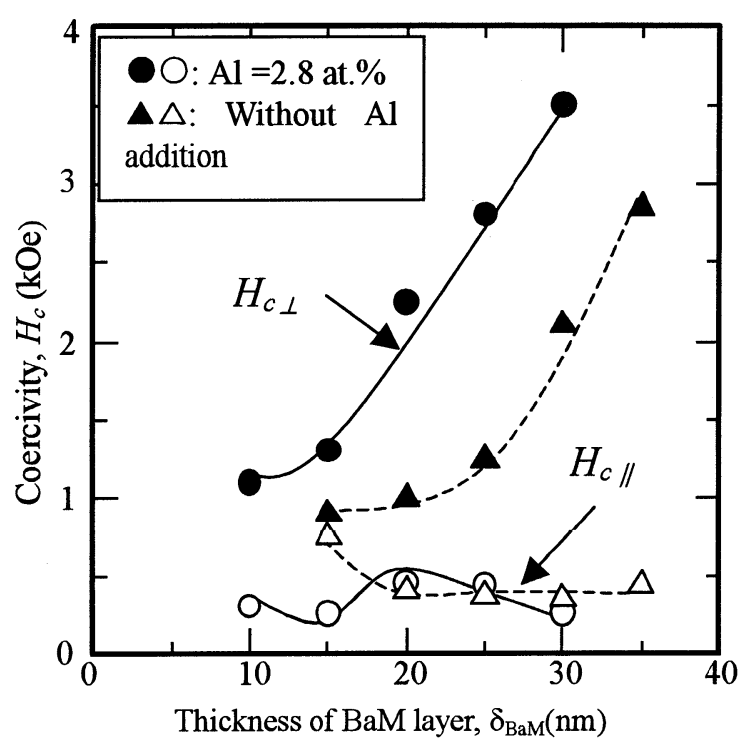

Fig. 4 Dependence of coercivity, $H_{c}$ of $\mathrm{BaM}$ and Al-BaM films as a function of the thickness of BaM layer. 


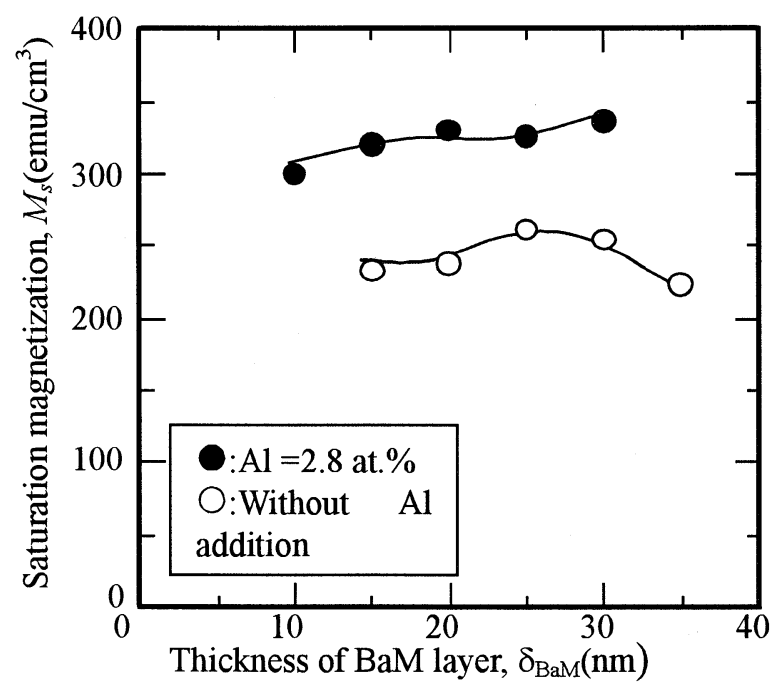

Fig. 5 Dependence saturation magnetization, $M_{s}$ of $\mathrm{BaM}$ and Al-BaM film as a function of the thickness of BaM layer.

squareness $\left(S_{\|}\right)$remains almost constant for any amount of Al. From these figures, it is clear that BaM film with 2.8 at. \% Al shows the highest coercivity and squareness in perpendicular direction among the $\mathrm{Al}$-added $\mathrm{BaM}$ films. This led the authors to concentrate further interest on $\mathrm{BaM}$ film with 2.8 at.\% Al.

$\mathrm{BaM}$ film with 2.8 at.\% Al shows better magnetic properties than that of $\mathrm{BaM}$ film without any Al. Fig.4 shows that the $H_{c \perp}$ of $\mathrm{BaM}$ film with 2.8 at \% $\mathrm{Al}$ is greater than that of $\mathrm{BaM}$ film without any $\mathrm{Al}$ for any value of $\delta_{\mathrm{BaM}}$. For Al-BaM film the maximum $H_{c \perp}$ is about $3.5 \mathrm{kOe}$, which is greater than that of $\mathrm{BaM}$ film without $\mathrm{Al}(2.2 \mathrm{kOe})$ for a film thickness $\left(\delta_{\mathrm{BaM}}\right)$ of $30 \mathrm{~nm}$. Al can substitute the $\mathrm{Fe}$ atoms of $\mathrm{BaM}\left(\mathrm{BaFe}_{12} \mathrm{O}_{19}\right)$ and hence it may increase the coercivity ${ }^{(8)}$. However coercivity decreases with decreasing film thickness of $\mathrm{BaM}$ layer even for Al-added BaM films. Though it is not shown here, an inter-diffused layer in between the BaM layer and $a$-AlO underlayer was found from the XPS depth profile. Al diffuses to the BaM layer from the $a$-AlO underlayer. This increases the relative amount of $\mathrm{Al}$ in the $\mathrm{BaM}$ film especially in the $\mathrm{BaM} / a$-AlO interface region and reduces the coercivity when film thickness decreases.

Fig. 5 shows the dependence of saturation magnetization on thickness for both $\mathrm{BaM}$ and $\mathrm{Al}$-added $\mathrm{BaM}$ films. $\mathrm{BaM}$ film without $\mathrm{Al}$ possesses $M_{s}$ of about 225-250 $\mathrm{emu} / \mathrm{cm}^{3}$ but the BaM film with 2.8 at. \% Al shows higher $M_{s}$ values within a range of $300-335 \mathrm{emu} / \mathrm{cm}^{3}$. Though it is not confirmed but it can be assumed that $\mathrm{Al}$ may occupy the preferential $\mathrm{Fe}$ sites of the $\mathrm{BaM}$ crystal and hence causes the increase of $M_{s}$ values.

Again the remanent squareness ratio, $S$ of $\mathrm{BaM}$ film with 2.8 at. $\% \mathrm{Al}$ is also higher than that of the $\mathrm{BaM}$ film without any Al. $\quad S_{\perp}$ is found about 0.7 and 0.4 for

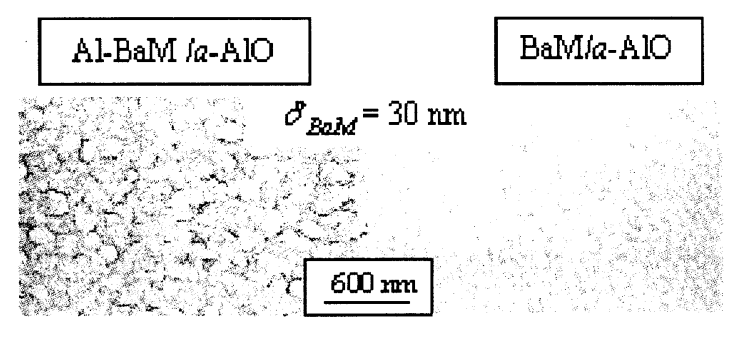

Fig. 6 SEM images of the BaM and Al-BaM film of $\delta_{\mathrm{BaM}}=30 \mathrm{~nm}$ deposited at a $T_{s}$ of $550^{\circ} \mathrm{C}$

$\mathrm{Al}-\mathrm{BaM}$ and $\mathrm{BaM}$ film respectively. All these magnetic data shows the better perpendicular magnetic anisotropy for the BaM film can be prepared with very few addition of Al.

Figure 6 shows the surface images of both $\mathrm{BaM}$ and Al-BaM film. From these images it is found that grains are coarser and grain size is larger in case of $\mathrm{Al}$ added $\mathrm{BaM}$ than those of $\mathrm{BaM}$ without $\mathrm{Al}$. It is also found from these images grains are agglomerated instead of isolated grains. This kind of microstructure is not so desired but addition of $\mathrm{Al}$ improves the magnetic properties as well as crystallographic texture. Further reduction of $T_{s}$ may improve the microstructure.

\section{Conclusion}

Ba-ferrite films with a small addition of $\mathrm{Al}$ and without any $\mathrm{Al}$ are deposited at $550^{\circ} \mathrm{C}$ onto a-AlO under-layer, which is deposited without substrate heating on $\mathrm{SiO}_{2} / \mathrm{Si}$ wafer. It is found that a small addition of $\mathrm{Al}$ can improve magnetic and crystallographic properties remarkably. Addition of Al produces the perfect c-axis orientation even for very thin film about $10 \mathrm{~nm}$ with a c-axis dispersion angle of 2.5 degree. It also increases the coercivity to $3.5 \mathrm{kOe}$ in perpendicular direction with a $M_{s}$ of $335 \mathrm{emu} / \mathrm{cm}^{3}$ and a remanent squareness of 0.7 in perpendicular direction.

\section{References}

1)T. L. Hylton, M. A. Parker, K. R. Coffey, R. Umphress, and J.K. Howard, J. Appl. Phys. 75, 5960 (1994).

2)A. Morisako, M. Matsumoto, and M. Naoe, IEEE. Trans. on Magn., 22, (No. 5), 1146 (1986).

3)A. Morisako, M. Matsumoto, and M. Naoe, J. Appl. Phys., 75, 5969 (1994).

4)A. Morisako, M. Matsumoto, and M. Naoe, IEEE. Trans. on Magn., 23, (No. 5), 2358 (1987).

5)A. Morisako, M. Matsumoto, and M. Naoe, J. Appl. Phys., 81, (No. 8), 4374 (1997).

6)K. H. J. Buschow, G. J. Long, and F. Grandjean, "High density digital recording," 182, (Kluwer, Dordrecht, 1992).

7)A. Morisako, N. N. Shams, Y. Miura, M. Matsumoto, S. H. Gee, M. H. Park, and Y.K. Hong, Presented at Int. Confc. on Magn.2003, (Elsevier Science, Italy, 2003) and Accepted to publish in J. Magn. Magn. Mater

8)J.Feng, N.Matsushita, K. Watanabe, S. Nakagawa, and M. Naoe, J. Appl. Phys, 85, (No.8), 6139 (1999)

Received: Oct. 23, 2003, Accepted: Feb. 10, 2004 